\title{
Research Advances in Generation, Hazard and Safety Technology of Static Electricity
}

\author{
Teng Xu and Hua Xie ${ }^{a}$ \\ School of Safety Engineering, Shenyang Aerospace University, Shenyang 110136, China \\ aemail: tedalanchong@163.com
}

Keywords: Static electricity, Safety technology, Electrostatic hazard.

\begin{abstract}
The importance of static electricity in today's world is known, which can initiate some new novel technologies of high electric drying, high electric thawing and electroosmosis dewatering in electrostatic application. However, their dangers are also evident. In addition, a large number of electrostatic accidents that can result in fire and explosion, constantly happen in the chemical industries in spite of the great perfection in the safety technology standard of chemical industries around the world. These incidents are coming up not only in the developed nations, but also in developing countries, which lead to enormous losses and deaths, and also endangered the local eco-environment. Therefore, how to apply static electricity safely have attracted much attention because electrical safety of modern industrialization have formed a tremendous international challenge.
\end{abstract}

\section{Introduction}

It is well known that static electricity is an electrical charge that can not move and an imbalance of positive and negative charges, which is created when two matters contact and separate each other within or on the surface of a material. The term static electricity is a relative one with current electricity, which can be eliminated through wires or other conductors to move away by means of an electric current or electrical discharge.

Static electricity can be recognized because it is able to be felt, heard and even seen. Currently, static electricity is generally applied in xerography, air filters (particularly electrostatic precipitators), automotive paints, photocopiers, paint sprayers, theaters, flooring in operating theaters, powder testing, printers, static bonding and aircraft refueling [1]. But, sometimes static electricity can create an annoying spark, which can startle, jolt you unexpectedly and even lead to fire and explosion. To eliminate the negative effects of static electricity, we should know what causes static electricity, how is it hazardous? Even more important, how can be it eliminated and controlled?

\section{Some Sources of Static Electricity}

When two bodies are in touch with each other, electrons may move from one to the other, which leaves an excess of positive charge on one, and an equal negative charge on the other. So, the body retains this imbalance charge when they are separated [2]. Some contact modes can result in the generation of static electricity, such as:

$>$ Contact-induced charge separation

$>$ Pressure-induced charge separation

$>$ Heat-induced charge separation

$>$ Charge-induced charge separation

In addition, some behaviors can also produce static electricity when:

$>$ Liquid flows through a pipe or hose, or through an opening in a pipe or hose

$>$ Spraying or coating

$>$ Blending or mixing

$>$ Filling tanks, drums, cans or pails 
$>$ Dry powdered material passes through chutes or pneumatic conveyors

$>$ Non-conductive conveyor belts or drive belts and moving appliances are plugged into electrical outlets

$>$ Walking across carpets and then touching a metal frame or door

$>$ And so on

We can effectively prevent and control the unwanted effects of static electricity when we know what causes static electricity. Therefore, the understanding of the above content is very important and helpful for safety management.

\section{Static Electricity Hazards}

Static electricity may result in all kinds of negative influence on the production and activity. But the most serious hazard of static electricity is the generation of electrosparks in an explosive or flammable environment, which can lead to an fire and explosion.

There are five types of static electricity discharges [3]:

Spark. It occurs between bodies at different electric potentials, as shown in Fig. 1.

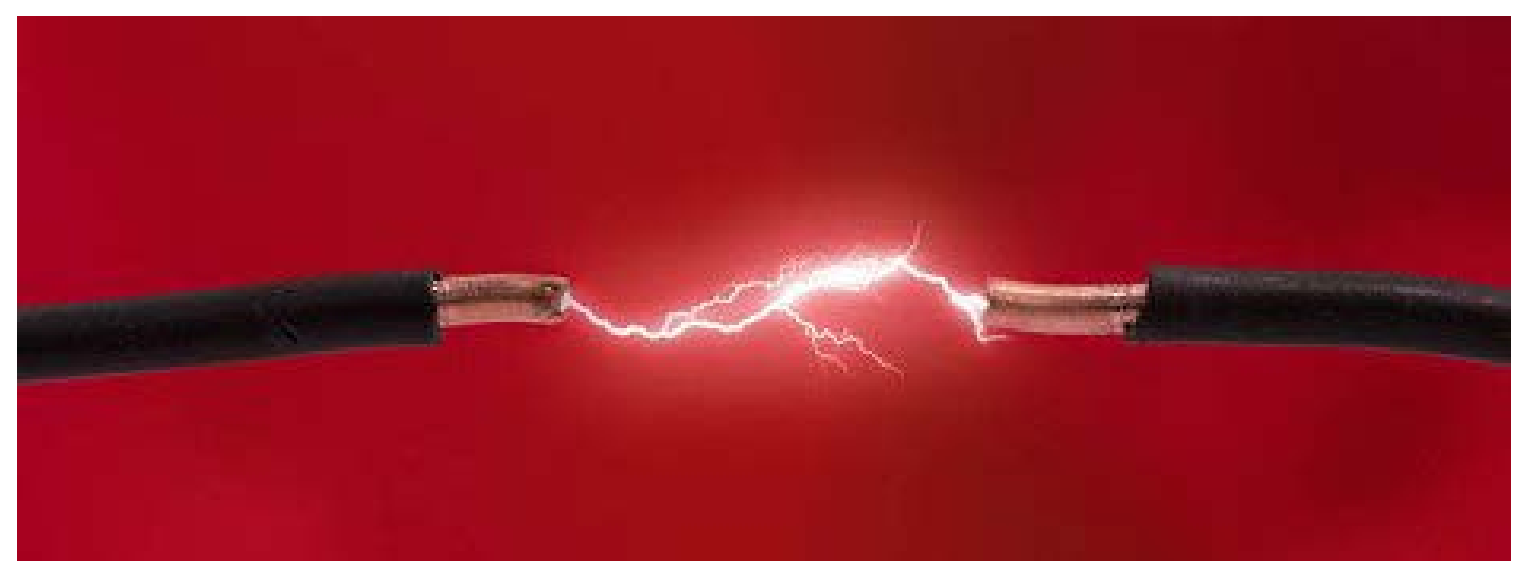

Fig. 1 Spark discharge

Brush Discharge. It stems from a nonconductive charged surface or highly charged nonconductive liquids (as shown in Fig. 2), which energy is about $4 \mathrm{~mJ}$.

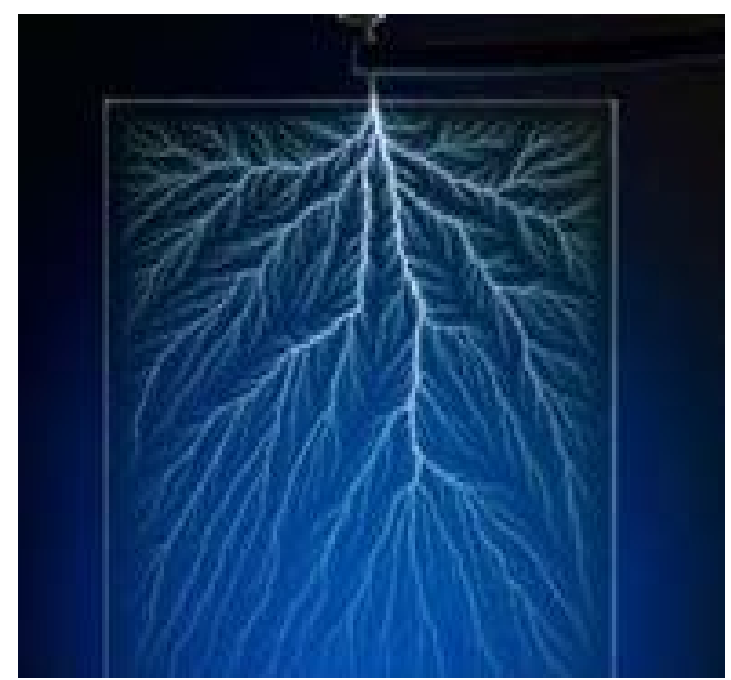

Fig. 2 Brush discharge

Propagating Brush Discharge. It occurs a large charge buildup between the opposite insulating surfaces, which is as a large-area capacitor, as shown in Fig. 3.. 


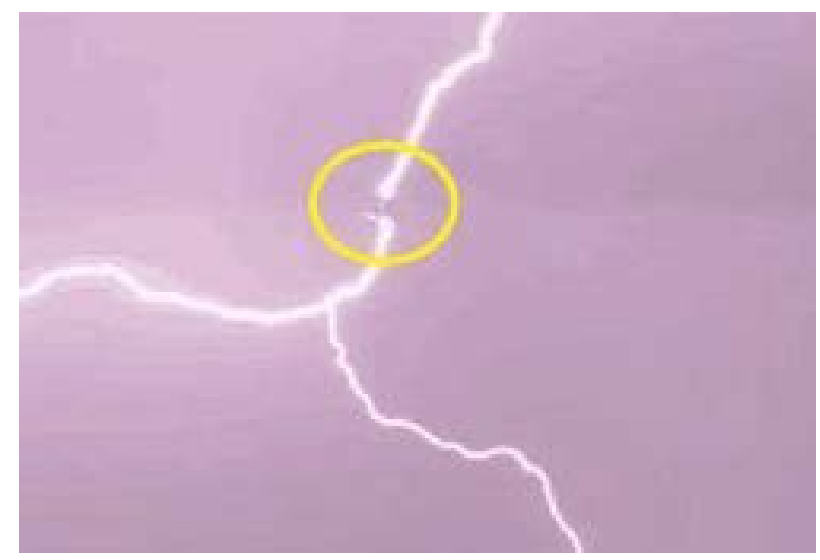

Fig. 3 Propagating brush discharge

Bulking Brush Discharge. It appears on surfaces and bodies of charged powders, which energy value depends on the volume of the powder and the charge magnitude, as shown in Fig. 4..

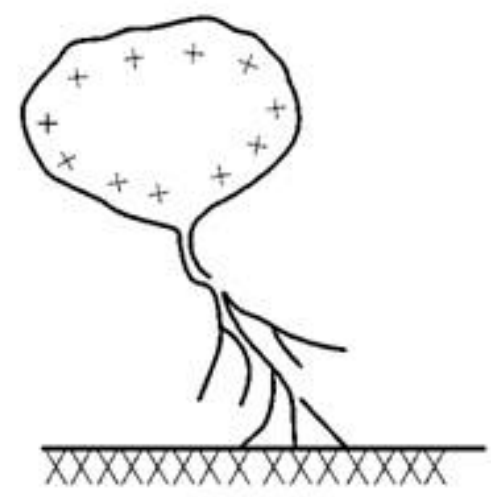

Fig. 4 Bulking brush discharge

Corona Discharge. It is regarded as non-hazardous, as shown in Fig. 5.

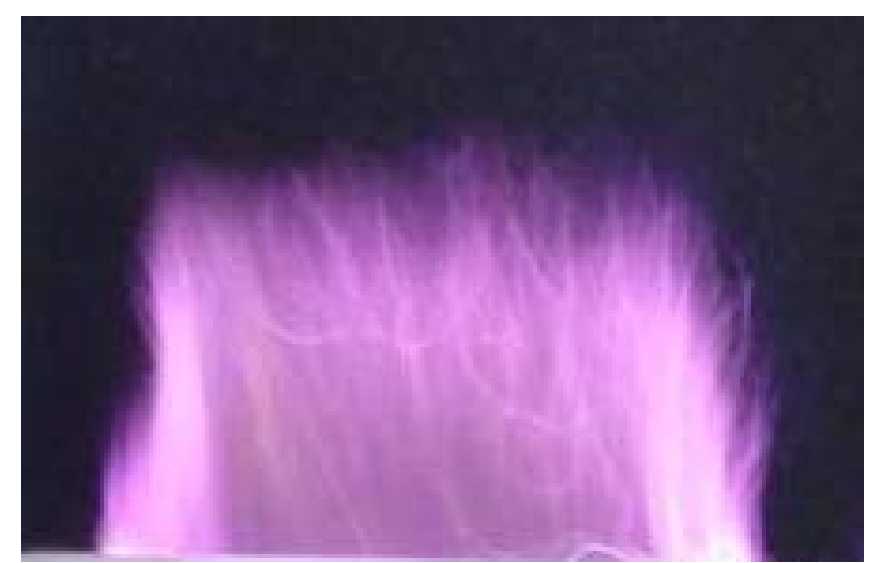

Fig. 5 Corona discharge

These discharge modes can produce energy, which may lead to an ignition hazard. Typical ignition energies for some hazardous chemicals are listed in Table 1. Minimum ignition energy (MIE) of these materials will be helpful for us to prevent and control accidents of fire and explosion to some extent.

\section{Elimination and Control of Static Electricity}

Most effective way of eliminating and controlling static electricity is to break up harmlessly before the static electricity discharge happens. The following way is the most common ones [4]: 
Bonding and grounding

$>$ Humidification

$>$ Static collectors

$>$ Additives

In addition, people also should do to prevent the buildup of static electricity, which can avoid the occurrence of accident. And it includes [5]:

$>$ Limit contact between moving bodies

$>$ Put a cotton layer between materials that tend to hold static electricity

$>$ Conductive footwear and clothing

$>$ Increase humidity

$>$ Ground the static by touching a grounded appliance, wiring a ground circuit, or by applying a neutralizing charge

Table 1. Minimum ignition energy of some materials.

\begin{tabular}{cc}
\hline Material Name & $\begin{array}{c}\text { Minimum Ignition Energy (MIE) } \\
\mathrm{mJ}\end{array}$ \\
\hline hydrogen & 0.017 \\
hydrocarbon vapors & $0.2-2$ \\
fine flammable dust & $1-50$ \\
coarse flammable dust & $40-1000$ \\
\hline
\end{tabular}

\section{Summary}

With the wide application of electronic equipment, the detriment of static electricity is gradually known by people. In order to prevent accidents generated by static electricity, it is very necessary for us to familiarize oneself with the genesis of static electricity. Therefore, the generation and hazard of static electricity have always been summarized in detail. Above all the control ways for protection against static electricity in the production and living are provided from a technology perspective. The current result may be helpful for the safety production management, which avoids new accidents to some extent.

\section{Acknowledgements}

This work was financially supported by the Undergraduate Innovation and Entrepreneurship Training Program of Liaoning Province (201310143026).

\section{References}

[1] Information on http://en.wikipedia.org/wiki/Static_electricity

[2] P.K. Dhogal. Basic Electrical Engineering, Tata McGraw-Hill. Vol. 1 (1986) p. 41

[3] J.J. Lowke. Journal of Physics D: Applied Physics Vol. 25 (1992), p. 202

[4] J.H. Kassebaum and R.A. Kocken. (1995). Petroleum and Chemical Industry 42nd Annual Conference, (1995), p. 105

[5] Information on http://www.wikihow.com/Remove-Static-Electricity 